\title{
Prepregnancy body mass indexes are associated with perinatal outcomes in females with preeclampsia
}

\author{
LINGLING JIANG ${ }^{*}$, JUAN LIN*, JIANYING YAN, XIAOQIAN LIN, QING HAN and HUALE ZHANG \\ Department of Obstetrics and Gynecology, Fujian Maternity and Child Health Hospital, \\ Affiliated Hospital of Fujian Medical University, Fuzhou, Fujian 350000, P.R. China
}

Received September 13, 2019; Accepted March 4, 2020

DOI: $10.3892 /$ etm.2020.8677

\begin{abstract}
The present study aimed to determine the clinical characteristics and perinatal outcomes of females with severe preeclampsia according to their pre-pregnancy body mass index (BMI). Data from 233 patients with severe preeclampsia were reviewed from the Inpatient Obstetrics Department. The data were divided into 3 groups according to the patients' pre-pregnancy BMI: Normal (BMI of 18-25 kg/m²; $\mathrm{n}=134$ ); underweight (BMI $\left.<18 \mathrm{~kg} / \mathrm{m}^{2} ; \mathrm{n}=15\right)$; and overweight and obese (BMI $\left.>25 \mathrm{~kg} / \mathrm{m}^{2} ; \mathrm{n}=84\right)$. The incidence of dyslipidemia, amniotic fluid abnormalities and neonatal hospitalizations in the group of females who were overweight or obese before pregnancy were higher than those in the other groups (all $\mathrm{P}<0.05$ ). In conclusion, the presence of dyslipidemia, excessive weight and obesity prior to pregnancy in patients with severe preeclampsia was associated with maternal and perinatal outcomes.
\end{abstract}

\section{Introduction}

Preeclampsia is a hypertensive multi-organ disorder of pregnancy with an immense adverse impact on maternal and perinatal health. Obesity, lipid metabolism disorders and oxidative stress have been reported to contribute to the pathophysiology of preeclampsia, but the exact mechanisms have remained elusive. Research is underway to elucidate the risk factors, the immunological aspects, as well as a definitive management protocol for preeclampsia (1).

Obesity has become a significant health issue worldwide (2), and an elevated body mass index (BMI) prior to pregnancy is associated with an increased risk of obstetrical complications,

Correspondence to: Dr Jianying Yan, Department of Obstetrics and Gynecology, Fujian Maternity and Child Health Hospital, Affiliated Hospital of Fujian Medical University, 18 Daoshan Road, Fuzhou, Fujian 350000, P.R. China

E-mail: yanjy2004@yeah.net

${ }^{*}$ Contributed equally

Key words: preeclampsia, obesity, oxidative stress, free fatty acids including gestational diabetes, necessity for cesarean sections, macrosomia, stillbirth and preeclampsia (3-7). Obesity is a well-recognized risk factor for preeclampsia $(8,9)$. The risk of preeclampsia is markedly elevated in females with high pre-pregnancy BMIs (10). However, the mechanisms linking preeclampsia and body weight prior to pregnancy have remained fully elusive. Being overweight prepregnancy or obese during pregnancy increases the metabolic demands on the body and changes in estrogen and progesterone levels inherent to pregnancy may lead to changes in blood lipid levels, disorders of lipid metabolism and imbalance of oxidation and anti-oxidation. DNA damage to vascular endothelial cells is positively correlated with increased serum triglyceride, total cholesterol and low-density lipoprotein levels and high triglyceride levels increase the risk of pregnancy-induced hypertension and gestational diabetes $(11,12)$. Dyslipidemia is a common feature of obesity and preeclampsia (10). Thus, it was hypothesized that prepregnancy BMI may be associated with lipid profile and with the pregnancy outcomes in patients with preeclampsia. In the present study, the clinical data of patients with severe preeclampsia admitted to our hospital over 1 year were retrospectively analyzed to identify the possible associations between pre-pregnancy weight, blood lipid levels and pregnancy complications in these patients.

\section{Patients and methods}

Patients. Data were collected from the clinical records of 233 Chinese females with severe preeclampsia who came to the Fujian Maternity and Child Health Hospital (Fuzhou, China) for delivery between October 2016 and October 2017. The mean age of the patients was 31.61 years (range, 18-48 years). Prepregnancy BMIs were calculated by dividing the body weight in kilograms by the squared body height in meters and the data were grouped according to their values (normal, BMI between 18 and $25 \mathrm{~kg} / \mathrm{m}^{2}, \mathrm{n}=134$; underweight, BMI $<18 \mathrm{~kg} / \mathrm{m}^{2}, \mathrm{n}=15$; and overweight and obese, BMI $>25 \mathrm{~kg} / \mathrm{m}^{2}$, $\mathrm{n}=84$ ). Data on the pre-pregnancy BMI were sourced from the medical records of the first antenatal visit of the patients included. A clinician diagnosed and classified preeclampsia as published (1). Severe preeclampsia was diagnosed based on the presence of the following criteria: i) An elevated systolic blood pressure (BP) of $\geq 160 \mathrm{mmHg}$ or a diastolic BP of $\geq 110 \mathrm{mmHg}$; ii) proteinuria of $\geq 3 \mathrm{~g} / 24 \mathrm{~h}$ (without urinary 
Table I. Clinical indicators of pregnant females.

\begin{tabular}{lccr}
\hline Item & $\begin{array}{c}\text { Underweight prior } \\
\text { to pregnancy }(\mathrm{n}=15)\end{array}$ & $\begin{array}{c}\text { Normal weight prior } \\
\text { to pregnancy }(\mathrm{n}=134)\end{array}$ & $\begin{array}{c}\text { Overweight and obese } \\
\text { prior to pregnancy }(\mathrm{n}=84)\end{array}$ \\
P-value
\end{tabular}

BMI, body mass index.

tract infection); and iii) abnormal liver or kidney function or thrombocytopenia. All patients had single pregnancies and underwent caesarean sections to deliver their babies. Data from patients with other pregnancies or surgical complications were excluded. Informed consent was obtained from patients and the local Institutional Review Board approved the study protocol (approval no. FMCH-2014-061).

Treatment and data collection. Following admission for delivery, the patients with severe preeclampsia were advised to rest on their left side. During hospitalization, symptomatic support for treatment of spasms was provided to attain appropriate hypotension, reasonable diuresis, proper sedation and correction of hypoalbuminemia and other associated conditions. Peripheral vein blood $(3 \mathrm{ml})$ was collected from the arm in the morning after overnight fasting for laboratory tests. The sera were obtained after centrifugation at room temperature for $15 \mathrm{~min}$ at $1,006.2 \mathrm{x} \mathrm{g}$ then stored at $-70^{\circ} \mathrm{C}$ until further experiments. Serum triglyceride and total cholesterol levels were determined from the samples using enzyme-coupled colorimetry. At the time of caesarean section, neonatologists were involved in resuscitations. Birth gestational age, body mass and Apgar scores were recorded. Quality of amniotic fluid was assessed by visual inspection. Amniotic fluid was classified as normal if it was clear or tinted-yellow. In the presence of meconium (greenish or brownish discoloration), amniotic fluid was classified as abnormal. The number of neonates hospitalized for obstetric complications in each group was also recorded.

Statistical analysis. All calculations were performed using SPSS for Windows 17.0 (SPSS, Inc.). Values are expressed as the mean \pm standard deviation or $n(\%)$. Categorical data were compared between the three groups using a $\chi^{2}$ test and continuous data by means of one-way analysis of variance with Tukey's post-hoc test. $\mathrm{P}<0.05$ was considered to indicate a statistically significant difference.

\section{Results}

General patient characteristics. In total, 15 patients were underweight, 134 had normal weight and 84 were overweight or obese prior to pregnancy. The mean age of underweight patients was $28.133 \pm 5.475$ years, of normal weight patients was $31.729 \pm 5.077$ years and of overweight and obese patients was $32.073 \pm 5.197$ years. Details of included patients are presented in Table I. There were no statistically significant intergroup differences between maternal and gestational ages, number of pregnancies, number of births and weight gain during pregnancy. The mean prepregnancy BMI in the overweight and obese group was significantly higher $\left(27.881 \pm 3.219 \mathrm{~kg} / \mathrm{m}^{2}\right)$ than that in the control group $\left(21.688 \pm 1.745 \mathrm{~kg} / \mathrm{m}^{2}\right)$ and that in the underweight group $\left(17.095 \pm 0.761 \mathrm{~kg} / \mathrm{m}^{2} ; \mathrm{P}<0.05\right.$ for all).

Blood lipid levels in each group. As presented in Table II, the mean maternal serum triglycerides were $6.336 \pm 0.831 \mathrm{mmol} / 1$ in the overweight and obese group, $4.053 \pm 0.482 \mathrm{mmol} / 1$ in the normal weight group and $3.133 \pm 0.390 \mathrm{mmol} / 1$ in the underweight group. Compared with those of the patients who were underweight or had a normal weight prior to pregnancy, the triglyceride levels of the patients who were overweight or obese prior to pregnancy were significantly higher $(\mathrm{P}<0.05)$. In addition, the mean triglyceride levels in the normal weight group prior to pregnancy were significantly higher than those in the underweight group. The mean maternal serum total cholesterol level was highest in the overweight and obese group, followed by that in the normal weight group, and lowest in the underweight group and the differences were statistically significant $(\mathrm{P}<0.05$; Table II).

Amniotic fluid quality in each group. Data on amniotic fluid quality are provided in Table III. In the overweight and obese group, 54 subjects had normal amniotic fluid and 30 had abnormalities (35.7\%). In the normal-weight group, 108 subjects had normal amniotic fluid and 26 had abnormalities (19.4\%). In the underweight group, 14 subjects had normal amniotic fluid and one had abnormalities $(6.6 \%)$. The probability of an amniotic fluid anomaly in the overweight and obese group was higher than that in the underweight and normal-weight groups $(\mathrm{P}<0.05)$. At the same time, the probability of an amniotic fluid anomaly in the normal-weight group was higher than that in the underweight group $(\mathrm{P}<0.05)$.

Neonate hospitalization in each group. In the overweight and obese group, 39 newborns were hospitalized and 45 (46.4\%) were not. In the normal-weight group, 33 newborns were 
Table II. Blood lipid levels in each group.

\begin{tabular}{|c|c|c|c|c|c|c|}
\hline Parameter & $\begin{array}{l}\text { Normal } \\
\text { range }^{\mathrm{d}}\end{array}$ & $\begin{array}{c}\text { Underweight } \\
\text { before pregnancy }\end{array}$ & $\begin{array}{l}\text { Normal weight } \\
\text { before pregnancy }\end{array}$ & $\begin{array}{l}\text { Overweight and obese } \\
\text { before pregnancy }\end{array}$ & P-value & Post-hoc test \\
\hline Triglycerides (mmol/l) & $\begin{array}{l}\text { Normal: }<1.7 \\
\text { Borderline: } 1.7-2 \\
\text { High 2-5.6 } \\
\text { Very high }>5.6\end{array}$ & $3.133 \pm 0.390$ & $4.053 \pm 0.482$ & $6.336 \pm 0.831$ & $<0.0001$ & $\begin{array}{l}<0.0001^{\mathrm{a}} \\
<0.0001^{\mathrm{b}} \\
<0.0001^{\mathrm{c}}\end{array}$ \\
\hline Total cholesterol (mmol/l) & $\begin{array}{l}\text { Normal: }<5.2 \\
\text { Borderline: } 5.2-6.2 \\
\text { High: }>6.2\end{array}$ & $4.536 \pm 0.278$ & $5.866 \pm 0.552$ & $6.937 \pm 0.886$ & $<0.0001$ & $\begin{array}{l}<0.0001^{\mathrm{a}} \\
<0.0001^{\mathrm{b}} \\
<0.0001^{\mathrm{c}}\end{array}$ \\
\hline
\end{tabular}

${ }^{\mathrm{a} U n d e r w e i g h t ~ v s . ~ n o r m a l ~ w e i g h t ~ p r i o r ~ t o ~ p r e g n a n c y ; ~}{ }^{\mathrm{b} U n d e r w e i g h t ~ v s . ~ o b e s i t y ~ p r i o r ~ t o ~ p r e g n a n c y ; ~}{ }^{\mathrm{C}}$ Normal weight vs. obesity prior to pregnancy; ${ }^{d}$ Reference values based on data from Fujian Maternity and Child Health Hospital, Affiliated Hospital of Fujian Medical University. One-way analysis of variance with Tukey's post hoc test was used for statistical comparisons.

Table III. Amniotic fluid quality in each group.

\begin{tabular}{lcccc}
\hline $\begin{array}{c}\text { Underweight } \\
\text { Amniotic } \\
\text { fluid }\end{array}$ & $\begin{array}{c}\text { Normal weight } \\
\text { prior to pregnancy } \\
(\mathrm{n}=15)\end{array}$ & $\begin{array}{c}\text { Overweight and } \\
\text { obese prior to } \\
\text { pregnancy }(\mathrm{n}=84)\end{array}$ & $\begin{array}{c}\text { P-value for the } \\
\text { difference between } \\
\text { the three groups }\end{array}$ \\
\hline Normal & 14 & 108 & 54 & 0.006 \\
Abnormal & 1 & 26 & 30 & 5 \\
\hline
\end{tabular}

Table IV. Neonate hospitalization rate in each group.

A, Data in each group

\begin{tabular}{lccc}
\hline $\begin{array}{l}\text { Neonate } \\
\text { hospitalizations }\end{array}$ & $\begin{array}{c}\text { Underweight } \\
\text { prior to pregnancy } \\
(\mathrm{n}=15)\end{array}$ & $\begin{array}{c}\text { Normal weight } \\
\text { prior to pregnancy } \\
(\mathrm{n}=134)\end{array}$ & $\begin{array}{c}\text { Overweight and } \\
\text { obese prior to } \\
\text { pregnancy }(\mathrm{n}=84)\end{array}$ \\
\hline Yes & 1 & 33 & 39 \\
No & 14 & 101 & 45 \\
$\chi^{2}(\mathrm{P}-\mathrm{value})$ & $15.940(0.003)$ & & 73 \\
\end{tabular}

$\mathrm{B}$, Inter-group comparison

\begin{tabular}{|c|c|c|c|}
\hline Group & Group & $\chi^{2}$ & P-value \\
\hline Normal weight prior to pregnancy & Overweight and obese prior to pregnancy & 11.095 & 0.0008 \\
\hline Underweight prior to pregnancy & Overweight and obese prior to pregnancy & 8.357 & 0.003 \\
\hline Underweight prior to pregnancy & Normal weight prior to pregnancy & 2.471 & 0.115 \\
\hline
\end{tabular}

hospitalized and $101(24.6 \%)$ were not. In the underweight group, only one newborn was hospitalized and 14 (93.4\%) were not. The probability of neonatal hospitalization in the overweight and obese group was significantly higher than that in the underweight and normal-weight groups $(\mathrm{P}<0.05)$. However, no significant differences in the number of hospitalized neonates between the normal-weight and underweight groups were determined (Table IV).

\section{Discussion}

Preeclampsia, which occurs in $2-7 \%$ of all pregnancies, is characterized by hypertension during pregnancy and the development of proteinuria (13). However, its pathogenesis remains to be fully elucidated.

Obesity has become a global health issue and a large number of females are overweight and obese during childbearing age. 
A study indicated that the $18.5 \%$ of pregnant females in the USA develop obesity and that $38.3 \%$ of these subjects go on to develop gestational hypertension, gestational diabetes, respiratory complications and blood clots (14). Another USA based study (15) demonstrated that obesity in full-term pregnancy accounts for up to $25 \%$ of stillbirths, and obesity may also affect the safety of mothers (5).

On the metabolic side, maternal variables, including insulin resistance, high lipid profiles, increased inflammatory mediators and associated endothelial dysfunction factors, differ between females who are overweight and those who are not, and these factors have roles in the pathogenesis of preeclampsia by increasing the susceptibility of the maternal vasculature to placental derived factors (16). A number of studies have indicated that dyslipidemia is one of the clinical manifestations of preeclampsia and that it is directly involved in the pathogenesis of preeclampsia (17). Females with obesity also present with dyslipidemia (18). Obesity is frequently accompanied by an increase in fat cell size. This causes changes in adipokines, including a reduction in adiponectin and an increase in tumor necrosis factor $\alpha$ and free fatty acids (19).

Obesity is commonly accompanied by dyslipidemia, which is characterized by elevated blood glucose and insulin (20). Normal fetal growth and development require a series of adaptive changes in the mother to maintain a healthy environment during pregnancy. Fat accumulates during the early pregnancy stages and hyperlipidemia develops during middle to late pregnancy, but these metabolic changes are exaggerated in females with preeclampsia (8). Lipid metabolic disorders may be severe in females with preeclampsia who were overweight or obese prior to pregnancy.

Obesity has been considered a risk factor for preeclampsia (21), but few studies have analyzed the association between prepregnancy BMI and abnormal lipid profiles in pregnant females $(22,23)$. A prospective study on 225 females by Scifres et al (22) demonstrated that obese females have significantly higher atherogenic profiles than normal-weight females in the early stages of pregnancy. Another study by Farias et al (23) suggested that overweight and obese females have higher mean serum triglyceride, total cholesterol and low-density lipoprotein levels than normal-weight females. Villa et al (24) demonstrated that the levels of free fatty acids are increased in patients with preeclampsia. Sharmani et al (25) demonstrated, in a case-controlled study of overweight preeclamptic women and overweight normotensive women, that serum triglyceride and total cholesterol levels are higher in overweight patients with severe preeclampsia. In the present study of severe preeclampsia patients, the results indicated that patients with higher prepregnancy weight (overweight and obese) have significantly higher serum triglyceride and total cholesterol levels as compared to normal weight women.

Maternal obesity is a risk factor for birth trauma and low Apgar scores, and it may contribute to numerous factors associated with neonatal morbidity $(26,27)$. The present study suggested that the probability of an amniotic fluid anomaly in females who are overweight or obese is higher than that in other subjects with severe preeclampsia. The probability of neonate hospitalization if the mother was overweight or obese was also higher than that in the other groups.

Adverse perinatal outcomes may occur due to high pre-pregnancy BMIs. Choi et al (28) confirmed that being underweight prepregnancy is a risk factor for neonatal complications. In the present study, the probability of hospitalization in neonates from mothers who were overweight and obese was higher than that in the other groups.

Obesity is a worldwide epidemic (29). Vieira et al (30) indicated that obesity may be included in prediction algorithms for preeclampsia, although the pathogenesis of preeclampsia remains to be fully elucidated. The risk of preeclampsia rises in females with high prepregnancy BMIs (8). Instead, females with low BMIs rarely develop preeclampsia (10). The retrospective nature of the present study did not allow any conclusions to be drawn regarding the exact mechanism of preeclampsia in the study population. It may be postulated that the pathophysiology of preeclampsia involves oxidative stress and dyslipidemia, and in another study, it was demonstrated that the serum levels of free fatty acids in females with preeclampsia are higher than those in control groups, and that the levels of oxidative stress damage are high in their placental mitochondria (31). The association between obesity and oxidative stress in preeclampsia patients deserves further study. Another limitation of the present study was the lack of a control group, and it was not possible to perform a comparison with the effects of prepregnancy body weights on perinatal outcomes in patients not suffering from preeclampsia.

In conclusion, the results of the present study indicate that severe preeclamptic females with excess prepregnancy weight or obesity have significantly higher incidences of dyslipidemia, amniotic fluid abnormalities and neonatal hospitalizations. Further studies are required to fully elucidate the impact of obesity on pregnancy in order to improve maternal and neonatal outcomes and prevent the occurrence of preeclampsia.

\section{Acknowledgements}

Not applicable.

\section{Funding}

The current study was supported by a Key Clinical Specialty Discipline Construction (Fujian, P.R. China) grant (2015; grant. no. 593).

\section{Availability of data and materials}

The datasets used and/or analyzed during the present study are available from the corresponding author on reasonable request.

\section{Authors' contributions}

LJ and JL conceived and designed the study. JY, XL, QH and $\mathrm{HZ}$ were involved in data collection and data interpretation. $\mathrm{XL}$ was involved in data analysis. LJ and JL were involved in the writing of the manuscript. JY was involved in the editing of the manuscript. All authors read and approved the final manuscript.

\section{Ethics approval and consent to participate}

The Ethics Committee of Fujian Maternity and Children's Hospital, Affiliated Hospital of Fujian Medical University 
(Fuzhou, China) approved this retrospective study (approval no. FMCH-2014-061). Informed written consent was obtained from all patients for the surgical procedures. For the present study, patient consent was waived, as it was a retrospective analysis, with no direct contact between the authors and the patients, and personal privacy was protected through anonymization.

\section{Patient consent for publication}

Not applicable.

\section{Competing interests}

The authors declare that they have no competing interests.

\section{References}

1. Rana S, Lemoine E, Granger JP and Karumanchi SA: Preeclampsia pathophysiology, challenges, and perspectives. Circ Res 124: 1094-1112, 2019.

2. Obesity: Preventing and managing the global epidemic. Report of a WHO Consultation World Health Organ Tech Rep Ser 894: i-xii, 1-253, 2000.

3. Rosenberg TJ, Garbers S, Chavkin W and Chiasson MA: Prepregnancy weight and adverse perinatal outcomes in an ethnically diverse population. Obstet Gynecol 102: 1022-1027, 2003.

4. Cedergren MI: Maternal morbid obesity and the risk of adverse pregnancy outcome. Obstet Gynecol 103: 219-224, 2004.

5. Weiss JL, Malone FD, Emig D, Ball RH, Nyberg DA, Comstock CH, Saade G, Eddleman K, Carter SM, Craigo SD, et al: Obesity, obstetric complications and cesarean delivery rate-a population-based screening study. Am J Obstet Gynecol 190: 1091-1097, 2004.

6. Ramos GA and Caughey AB: The interrelationship between ethnicity and obesity on obstetric outcomes. Am J Obstet Gynecol 193: 1089-1093, 2005.

7. Nohr EA, Bech BH, Davies MJ, Frydenberg M, Henriksen TB and Olsen J: Prepregnancy obesity and fetal death: A study within the Danish National Birth Cohort. Obstet Gynecol 106: 250-259, 2005.

8. Bodnar LM, Ness RB, Markovic N and Roberts JM: The risk of preeclampsia rises with increasing prepregnancy body mass index. Ann Epidemiol 15: 475-482, 2005.

9. Kabiru W and Raynor BD: Obstetric outcomes associated with increase in BMI category during pregnancy. Am J Obstet Gynecol 191: 928-932, 2004.

10. Walsh SW: Obesity: A risk factor for preeclampsia. Trends Endocrinol Metab 18: 365-370, 2007.

11. Shen H, Liu X, Chen Y, He B and Cheng W: Associations of lipid levels during gestation with hypertensive disorders of pregnancy and gestational diabetes mellitus: A prospective longitudinal cohort study. BMJ Open 6: e013509, 2016.

12. Geraghty AA, Alberdi G, O'Sullivan EJ, O'Brien EC, Crosbie B, Twomey PJ and McAuliffe FM: Maternal and fetal blood lipid concentrations during pregnancy differ by maternal body mass index: Findings from the ROLO study. BMC Pregnancy Childbirth 17: 360, 2017.

13. Steegers EA, von Dadelszen P, Duvekot JJ and Pijnenborg R: Pre-eclampsia. Lancet 376: 631-644, 2010.

14. Yogev $\mathrm{Y}$ and Catalano PM: Pregnancy and obesity. Obstet Gynecol Clin North Am 36: 285-300, viii, 2009.
15. Yao R, Ananth CV, Park BY, Pereira L and Plante LA; Perinatal Research Consortium: Obesity and the risk of stillbirth: A population-based cohort study. Am J Obstet Gynecol 210: 457.e1-e9, 2014.

16. Jarvie E, Hauguel-de-Mouzon S, Nelson SM, Sattar N, Catalano PM and Freeman DJ: Lipotoxicity in obese pregnancy and its potential role in adverse pregnancy outcome and obesity in the offspring. Clin Sci (Lond) 119: 123-129, 2010.

17. Yan J and Jiang L: Expression of advanced glycation end products in placenta and concentration in maternal and umbilical serum in pre-eclampsia. J Obstet Gynaecol Res 41: 843-849, 2015.

18. Ramsay JE, Ferrell WR, Crawford L, Wallace AM, Greer IA and Sattar N: Maternal obesity is associated with dysregulation of metabolic, vascular, and inflammatory pathways. J Clin Endocrinol Metab 87: 4231-4237, 2002.

19. Abhari FR, Ghanbari Andarieh M, Farokhfar A and Ahmady S: Estimating rate of insulin resistance in patients with preeclampsia using HOMA-IR index and comparison with nonpreeclampsia pregnant women. Biomed Res Int 2014: 140851, 2014.

20. Kabat GC, Kim MY, Chlebowski RT, Vitolins MZ, Wassertheil-Smoller S and Rohan TE: Serum lipids and risk of obesity-related cancers in postmenopausal women. Cancer Causes Control 29: 13-24, 2018.

21. Marshall NE, Guild C, Cheng YW, Caughey AB and Halloran DR: Racial disparities in pregnancy outcomes in obese women. J Matern Fetal Neonatal Med 27: 122-126, 2014.

22. Scifres CM, Catov JM and Simhan HN: The impact of maternal obesity and gestational weight gain on early and mid-pregnancy lipid profiles. Obesity (Silver Spring) 22: 932-938, 2014.

23. Farias DR, Franco-Sena AB, Vilela A, Lepsch J, Mendes RH and Kac G: Lipid changes throughout pregnancy according to pre-pregnancy BMI: Results from a prospective cohort. BJOG 123: 570-578, 2016.

24. Villa PM, Laivuori H, Kajantie E and Kaaja R: Free fatty acid profiles in preeclampsia. Prostaglandins Leukot Essent Fatty Acids 81: 17-21, 2009.

25. Sharmani SH, Tangestani A, Faraji A, Zahiri Z and Amiri A: Role of dyslipidemia in preeclamptic overweight pregnant women. Iran J Reprod Med 10: 105-112, 2012.

26. Maier JT, Schalinski E, Gauger U and Hellmeyer L: Antenatal body mass index (BMI) and weight gain in pregnancy-its association with pregnancy and birthing complications. J Perinat Med 44: 397-404, 2016.

27. Gao X, Yan Y, Xiang S, Zeng G, Liu S, Sha T, He Q, Li H, Tan S, Chen C, et al: The mutual effect of pre-pregnancy body mass index, waist circumference and gestational weight gain on obesity-related adverse pregnancy outcomes: A birth cohort study. PLoS One 12: e0177418, 2017.

28. Choi SK, Park IY and Shin JC: The effects of pre-pregnancy body mass index and gestational weight gain on perinatal outcomes in Korean women: A retrospective cohort study. Reprod Biol Endocrinol 9: 6, 2011.

29. Avcı ME, Şanlıkan F, Çelik M, Avcı A, Kocaer M and Göçmen A: Effects of maternal obesity on antenatal, perinatal and neonatal outcomes. J Matern Fetal Neonatal Med 28: 2080-2083, 2015.

30. Vieira MC, Poston L, Fyfe E, Gillett A, Kenny LC, Roberts CT, Baker PN, Myers JE, Walker JJ, McCowan LM, et al: Clinical and biochemical factors associated with preeclampsia in women with obesity. Obesity (Silver Spring) 25: 460-467, 2017.

31. Yan JY and Xu X: Relationships between concentrations of free fatty acid in serum and oxidative-damage levels in placental mitochondria and preeclampsia. Zhonghua $\mathrm{Fu}$ Chan $\mathrm{Ke} \mathrm{Za}$ Zhi 47: 412-417, 2012 (In Chinese).

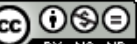

This work is licensed under a Creative Commons Attribution-NonCommercial-NoDerivatives 4.0 International (CC BY-NC-ND 4.0) License. 